
$\angle$ Research Square
Preprints are preliminary reports that have not undergone peer review.
They should not be considered conclusive, used to inform clinical practice,
or referenced by the media as validated information.

\title{
Mapping the Vector Abundance of Endemic Mosquito-Borne Diseases in Southern Quebec
}

Julie Allostry

Universite de Sherbrooke

Antoinette Ludwig ( $\nabla$ antoinette.ludwig@canada.ca )

Public Health Agency of Canada

Serge Olivier Kotchi

Public Health Agency of Canada https://orcid.org/0000-0002-4931-1489

François Rousseu

Universite de Sherbrooke

Richard Fournier

Universite de Sherbrooke

Research

Keywords: Public health, mosquitoes, zoonoses, vector-borne diseases, space-time modelling, southern Quebec, Culex pipiens-restuans, Ochlerotatus stimulans, Coquillettidia perturbans, Aedes vexans

Posted Date: August 24th, 2020

DOI: https://doi.org/10.21203/rs.3.rs-60838/v1

License: () This work is licensed under a Creative Commons Attribution 4.0 International License. Read Full License 


\section{Abstract}

Background: Climate change is increasing the dispersion of mosquitoes and the spread of viruses of which some mosquitoes are the main vectors. This increases the risk of humans coming into contact with infected mosquitoes and developing diseases with sometimes fatal consequences. In Quebec, the surveillance and management of endemic mosquito-borne diseases, such as West Nile virus or Eastern equine encephalitis, could be improved by mapping the areas of risk supporting vector populations. However, there is currently no active tool tailored to Quebec that can predict annual mosquito population abundances.

Methods: Our modelling approach is designed to meet this need. Four species of mosquitos were studied in this project for the period from 2003 to 2014 for the southern part of the province: Aedes vexans (VEX), Coquillettidia perturbans (CQP), Culex pipiens-restuans group (CPRg) and Ochlerotatus stimulans group (STMg) species. We used a mixed linear regression approach to model the abundances of each species or species groups as a function of meteorological and land cover variables.

Results: The best models incorporate, for CPRg, the agricultural land, grassland and woodland classes and the average minimum temperature in September of the previous year; for STMg, the urban and woodland classes and the mean precipitation in June; for CQP, urban areas and the mean precipitation in January and August; and finally, for VEX, the agricultural land class and the mean precipitation in January, February and September.

Conclusions: The models proved to be robust and precise over almost the entire study area, and the presence of significant climate variables for each of the species or species groups makes it possible to consider their use in predicting long-term spatial variations, based on climate and landscape change, in the abundance of mosquitoes potentially harmful to public health in southern Quebec.

Manuscript intended for publication in International J. of Health Geographics

\section{Background}

In Canada, the arbovirus most commonly transmitted to humans by mosquitoes is West Nile virus (WNV). The first human cases of WNV in Canada were identified in Ontario in 2002 and Quebec in 2003. In Canada, two major epidemics were observed in 2003 and 2007 with 1,481 and 2,215 cases, respectively [1]. Since then, the virus has continued to circulate in most Canadian provinces with varying impacts year after year. Seventy per cent to $80 \%$ of people who have WNV remain asymptomatic, but in 1-2\% of clinical cases, the consequences can be severe (encephalitis, encephalomyelitis, even death) [2]. Although rarer, other arboviruses transmissible to humans are also present in Canada, including Eastern equine encephalitis (EEE), with the first human case in Canada in Ontario in 2016 [3], St. Louis encephalitis virus (SLEV) and California serogroup (CSG) viruses. Of the many CSG viruses that exist, Cache Valley (CVV), Jamestown Canyon (JCV) and Snowshoe hare (SSHV) viruses are the only ones found in Canada [4, 5]. In Canada, managing health care and applying preventive measures fall under provincial jurisdiction. In the province of Quebec, the number of human cases of WNV has varied considerably from year to year, with 195 confirmed cases of infection in 2018, including 15 deaths [6]. No human cases of EEE have been observed in Quebec [7], but 82 human cases of CSG infection were observed in Quebec in 2017 and 17 in 2018 [8]. In Quebec, CSG viruses, EEE and WNV are on a watch list for health professionals, and WNV is a notifiable disease [9]. Better characterizing the risk associated with mosquitoes likely to transmit diseases to humans is, therefore, a public health issue for Canada in general, and Quebec in particular.

One of the tools of choice in public health decision making is the threat exposure risk map, in this case the spatial distribution of the mosquito population. It allows for better targeting and optimization of control (larviciding) or prevention (message to the public) programs in the region [10]. Modelling mosquito abundances is one way to predictively map exposure risks $[11,12,13]$. The variables employed for such mapping often involve the use of meteorological data, such as temperature and precipitation $[11,13,14,15,16,17,18,19,20]$, and land cover data, because the populations being modelled are arthropods, living organisms that are highly dependent on their environment and the prevailing weather conditions. The environmental data used as explanatory variables vary widely across studies and cover the following major themes: land cover and land use, vegetation indices, hydrographic indices, drainage indices, wetlands, slope and altitudes $[15,17,21]$.

In Quebec, Culex pipiens-restuans (CPR) is the main vector species for WNV [22]. It also has some vector competence for EEE [23, 24]. According to a study conducted in Illinois, CPR is fond in woodlands in particular and, to a lesser extent, in fields, grasslands and urban areas [25]. Still in Illinois, Jacob [26] indicated that CPR prefers to lay their eggs in the artificial and natural containers found mainly in urban areas.

Aedes vexans (VEX) is very abundant in southern Quebec. This species has some vector competence for WNV [27, 28, 29], EEE [23], SSHV [28] and JCV [23, 28, 30]. It spawns primarily in the temporary or more permanent aquatic areas that may form in agricultural areas and wetlands [31]. Other sources indicated that VEX prefer to develop in pools, shallow pasture ponds, woodlands and grasslands [32, 33].

Coquillettidia perturbans (CQP) larvae require aquatic plants, such as reeds or water lilies; they get oxygen from them by piercing their roots. It is, therefore, a species that requires permanent bogs or marshes for the larval stage of its life cycle [34]. However, while CQP is very common, not much more is known about the other environmental conditions necessary for their development. CQP has some known vector competence for EEE [23] primarily and for WNV [28] and JCV [30] secondarily.

Ochlerotatus stimulans, included in a group we call STMg, has known vector competence for JCV [23, 35] and SSHV [36]. The other species in the group, Ochlerotatus hexodontus, probably has less vector competence for JCV [37] and SSHV [38]. The environmental preferences of this species group are poorly documented. It seems that STMg prefers to spawn in vernal pools [39, 40]. 
Not all of these mosquito species have the same preferences in terms of larval habitat and climate sensitivity. For example, each species of mosquito will be more or less sensitive to variations in meteorological factors as diverse as the number of degree-days, the photoperiod, or intra- or interannual temperatures, depending on its biological characteristics and stage of development [5, 41, 42, 43, 44, 45, 46]. It is, therefore, essential that the models developed are speciesspecific [47] and combine spatial and temporal aspects $[11,13,19,20]$. Spatial variations will reflect environmental changes and major climate trends, and temporal variations will represent meteorological changes as well as landscape changes over time.

Our study, therefore, involved modelling the spatial distribution of CPR, STM, CQP and VEX mosquito populations as a function of land cover and meteorological variables in southern Quebec. More specifically, the objective of this paper was to develop a modelling method for mapping mean annual mosquito abundances in southern Quebec with a spatial model that uses landcover and meteorological data. The purpose of these models was to create maps of mean annual mosquito abundance, for each of the four species, to guide campaigns to prevent and control the spread of the diseases borne by the selected species. The sub-objectives were to (1) determine the relevant meteorological variables and land cover classes that characterize an environment conducive to the development of each species based on known entomological characteristics; (2) develop, for each of the four species or groups of species, a spatial model for predicting mean annual abundances based on these meteorological and environmental variables; and (3), map the annual mosquito abundances predicted by the model.

\section{Methods}

\section{Study area}

The study area located in southern Quebec spans 102,850 km² (Fig. 1). It was determined based on available mosquito sampling data and follows the human ecumene of the greater Montreal, Quebec City and Gatineau areas. Fifty per cent of traps are located in urban areas, $20 \%$ in woodlands, $15 \%$ in vegetated nontreed areas, $8.5 \%$ in agricultural areas, and the remaining $6.5 \%$ in other areas. The study area is crossed from southwest to northeast by the St. Lawrence River. Most of the areas south of the river are dense agricultural areas with some open woodlands and the odd wetland. North of the river, past a narrow agricultural strip, there is a forest area populated by mixed and coniferous forest whose density increases toward the north. According to the Köppen-Geiger classification [48], most of our study area has, in its southern part, a warm-summer humid continental climate (Dfb boreal climate), with the warmest month of the year (July) averaging below $22^{\circ} \mathrm{C}$, but more than four months averaging above $10{ }^{\circ} \mathrm{C}$. The temperature in the coldest four months varies between -38 and $0{ }^{\circ} \mathrm{C}$. The northern part of the study area has a subarctic climate (Dfc boreal climate). The average temperature in the warmest month is above $10{ }^{\circ} \mathrm{C}$ and below $22{ }^{\circ} \mathrm{C}$, that in the coldest month is between -38 and $0{ }^{\circ} \mathrm{C}$, and less than four months average above $10^{\circ} \mathrm{C}$. Precipitation is distributed evenly throughout the year. In these types of climates, the season of mosquito activity generally extends from May to September.

\section{Mosquito data}

There are approximately 80 species of mosquitoes in Canada $[40,49]$. To limit the number of mosquito species to be studied, we selected for our study four species that pose a potential public health risk: CPR, CQP, VEX and STM. Because of difficulties distinguishing Culex pipiens from Culex restuans morphologically, these species are very commonly grouped under the CPR group (CPRg); Oc. stimulans and Oc. hexodontus are also grouped together for this reason. The mosquito catch data came partly from the provincial program under the Institut national de Santé publique du Québec (INSPQ) and Quebec's Ministère de la Santé et des Services sociaux (MSSS) for the surveillance of mosquito-borne diseases in Quebec, and partly from the Public Health Agency of Canada (PHAC) using the database of a private company involved in mosquito control (GDG Environnement Ltd.). Trapping was conducted with Center for Disease Control (CDC) $\mathrm{CO}_{2}$ light traps. The dataset covers the years 2003 to 2016, but with varying intensity (significant variation in the number of catches by traps per year and in the traps location). To ensure that our data adequately reflect annual abundance, we selected traps that had operated for a minimum of 15 consecutive weeks during the mosquito season. A shorter period would not have been sufficient to represent annual abundances, and a longer period would have been too restrictive in the number of traps selected. The years 2003, 2004, 2005, 2013 and 2014 were the only one who meet this criterion.

\section{Environmental data}

The first category of environmental data used are the land cover class (LCC) layers derived from previously classified satellite (raster) data and vector data (Table 1). Eight LCCs were selected for our exercise based on our literature review: aquatic area (shallow and deep water), bare soil, urban/built-up, wetland, agricultural land, pasture/grassland, vegetated non-treed, and woodland. The raster layer processed by Agriculture and Agri-Food Canada (AAFC) [50] was used as a general base, and its classification was improved by the addition from multi-source data: The classified SPOT raster land cover of Canada south of the treeline provided by the Government of Canada $(\mathrm{GoC})$ [51] and two other layers in vector format were used for this purpose, namely the Ducks Unlimited Canada (DUC) [52] wetland map and Natural Resources Canada's National Hydrographic Network (NHN) [53]. The different sources of LCC data were combined using the following decision rule: in non-urban areas, the information provided by the AAFC layer prevailed. In urban areas, the information provided by the SPOT image prevailed over the AAFC image. The LCC was classified as a wetland if and only if the data provided by AAFC, SPOT and DUC all indicated the presence of a wetland. The LCC was classified as an aquatic area based on the NHN information, which prevailed over all other data sources. Around each trap, 1-km buffers were created from which the presence percentages for each LCC were extracted. The analyses were performed in PCI Geomatica [54] and ArcGIS [55].

Table 1: Sources and characteristics of predictor variables for modelling the abundance and the spatial distribution of Culex pipiens-restuans group, Aedes vexans, Coquilettidia perturbans and Ochlerotatus stimulans group in southern Quebec. 


\begin{tabular}{|c|c|c|c|c|}
\hline $\begin{array}{l}\text { Type of } \\
\text { data }\end{array}$ & Source & $\begin{array}{l}\text { Years } \\
\text { acquired }\end{array}$ & Accuracy & $\begin{array}{l}\text { Computed variables and } \\
\text { units }\end{array}$ \\
\hline & Mosquito catch data & & & \\
\hline \multirow{2}{*}{$\begin{array}{l}\text { Catch } \\
\text { count per } \\
\text { trap }\end{array}$} & PHAC and INSPQ + MSSS & $\begin{array}{l}2003 \text { to } \\
2016\end{array}$ & $\mathrm{~N} / \mathrm{A}$ & $\begin{array}{l}\text { Number of mosquitoes per } \\
\text { trap aggregated per year }\end{array}$ \\
\hline & Land cover and land use data & & & \\
\hline \multirow{4}{*}{$\begin{array}{l}\text { Classified } \\
\text { images }\end{array}$} & AAFC Annual Crop Inventory, GoC & 2011 to & $30 \mathrm{~m}$ & Land cover classes $(\%)$ \\
\hline & $\begin{array}{l}\text { https://open.canada.ca/data/en/dataset/ba2645d5-4458-414d-b196- } \\
\text { 6303ac06c1c9 }\end{array}$ & (6 images) & $\begin{array}{l}\text { (overall } \\
\text { classification } \\
\text { accuracy of } \\
85 \% \text { ) }\end{array}$ & 1 image per year \\
\hline & Classified SPOT Land Cover of Canada South of Treeline, NRCAN, GoC & Acquired & $20 \mathrm{~m}$ & \\
\hline & $\begin{array}{l}\text { https://open.canada.ca/data/en/dataset/d1fc6010-e2e7-401a-8dc1- } \\
\text { 544cd2ac0b03 }\end{array}$ & $\begin{array}{l}2005 \text { and } \\
2010 \\
(1 \text { image) }\end{array}$ & $\begin{array}{l}\text { (overall } \\
\text { classification } \\
\text { accuracy of } \\
71 \% \text { ) }\end{array}$ & \\
\hline \multirow{7}{*}{$\begin{array}{l}\text { Vector } \\
\text { data }\end{array}$} & DUC WL & Identified & $1: 20,000$ & \\
\hline & $\begin{array}{l}\text { https://www.donneesquebec.ca/recherche/fr/dataset/milieux-humides-du- } \\
\text { quebec }\end{array}$ & $\begin{array}{l}1999 \text { and } \\
2005\end{array}$ & & \\
\hline & & $\begin{array}{l}(1 \\
\text { shapefile) }\end{array}$ & & \\
\hline & NHN, NRCAN, GoC & $\begin{array}{l}\text { Identified } \\
\text { between }\end{array}$ & $1: 20,000$ & \\
\hline & $\begin{array}{l}\text { https://www.nrcan.gc.ca/science-and-data/science-and-research/earth- } \\
\text { sciences/geography/topographic-information/geobase-surface-water- } \\
\text { program-geeau/national-hydrographic-network/21361 }\end{array}$ & $\begin{array}{l}1999 \text { and } \\
2014\end{array}$ & & \\
\hline & & $\begin{array}{l}\text { ( } 1 \\
\text { shapefile) }\end{array}$ & & \\
\hline & Meteorological data & & & \\
\hline \multirow[t]{2}{*}{ Images } & Daily records at Environment Canada ground meteorological stations & \multirow{2}{*}{$\begin{array}{l}2002 \text { to } \\
2015\end{array}$} & \multirow{2}{*}{$\begin{array}{l}\text { Interpolation } \\
\text { resampled to } \\
1 \mathrm{~km}\end{array}$} & $\begin{array}{l}\text { Total annual and monthly } \\
\text { precipitation (mm) }\end{array}$ \\
\hline & https://climate.weather.gc.ca/historical_data/search_historic_data_e.html & & & $\begin{array}{l}\text { Minimum, mean and } \\
\text { maximum annual and } \\
\text { monthly temperatures }\left({ }^{\circ} \mathrm{C}\right)\end{array}$ \\
\hline
\end{tabular}

AAFC: Agriculture and Agri-Food Canada - PHAC: Public Health Agency of Canada - DUC: Ducks Unlimited Canada - GoC: Government of Canada - INSPQ: Institut national de santé publique du Québec - WL: Wetlands - MSSS: Ministère de la Santé et des Services sociaux - NHN: National Hydrographic Network

The second category of environmental data used is obtained from daily meteorological records at Environment Canada ground stations [56], interpolated with inverse distance weighting $[14,57]$ and resampled for every $1 \mathrm{~km}$ over the entire study area. One image per day is produced for the years 2002 to 2014 , inclusively. Four meteorological variables are calculated: minimum, mean and maximum daily temperatures and total daily precipitation. These variables are then averaged within a 1-km buffer around each trap to produce minimum, mean and maximum monthly and annual temperatures and mean monthly precipitation.

Table 2: List of inputs used as predictive variables for modelling the abundance and the spatial distribution of Culex pipiens-restuans group, Aedes vexans, Coquilettidia perturbans and Ochlerotatus stimulans group in southern Quebec. 


\begin{tabular}{|c|c|c|c|c|c|}
\hline \multirow{3}{*}{$\begin{array}{l}\text { Land cover variables } \\
\% \\
\text { Water }\end{array}$} & \multicolumn{5}{|c|}{ Meteorological variables } \\
\hline & \multirow{2}{*}{$\begin{array}{l}\text { Annual means } \\
\text { TNan }\end{array}$} & \multicolumn{4}{|c|}{ Monthly means } \\
\hline & & TNjan & TXjan & TYjan & Pjan \\
\hline Bare Soil & TXan & TNfeb & TXfeb & TYfeb & Pfeb \\
\hline Urban & TYan & TNmar & TXmar & TYmar & Pmar \\
\hline Wetland & Pan & TNapr & TXapr & TYapr & Papr \\
\hline Agri & & TNmay & TXmay & TYmay & Pmay \\
\hline Grassland & & TNjun & TXjun & TYjun & Pjun \\
\hline Vegetation & & TNjul & TXjul & TYjul & Pjul \\
\hline \multirow[t]{6}{*}{ Woodland } & & TNaug & TXaug & TYaug & Paug \\
\hline & & TNsep & TXsep & TYsep & Psep \\
\hline & & TNsep_1y & TXsep_1y & TYsep_1y & Psep_1y \\
\hline & & TNoct_1y & TXoct_1y & TYoct_1y & Poct_1y \\
\hline & & TNnov_1y & TXnov_1y & TYnov_1y & Pnov_1y \\
\hline & & TNdec_1y & TXdec_1y & TYdec_1y & Pdec_1y \\
\hline
\end{tabular}

Agri: Agricultural land; an: annual; TN: minimum temperatures; TX: maximum temperatures; TY: mean temperatures; P: mean precipitation; _1y: from previous year.

\section{Statistical analyses}

\section{Preparation of variables and univariate regression}

The predicted variables built for the prediction model were the sum of mosquitoes captured by traps by night of capture, for each trap, per year and for each species. The training data are essentially all the trapping data available for the years 2003, 2004, 2005 and 2013 . To meet the requirements of a normal residual error structure and homoscedasticity assumed in a linear gaussian model, we tested several possible transformations of the abundance data, and ultimately chose Box-Cox transformations. In addition, the variables extracted from the LCCs and meteorological images were standardized (mean=0, sd=1) to make them comparable in a multiple model. The name of the trap, unique according to its location, was introduced as a random factor in the linear regression to take into account repeated measures at the same locations across years.

To select relevant variables, the predictive variables were first screened by retaining only those variables having a significant effect on annual abundances

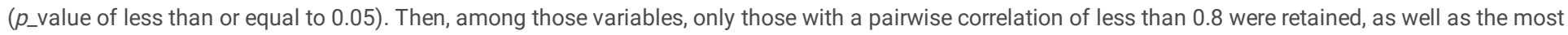
significant variable when the pairwise correlation coefficient was larger than 0.8 [14]. The final selection of the variables included in the models was based on three maximum variance inflation factor (VIF) thresholds: 3,5 and 10. The three VIF thresholds used were taken from compatible studies in the literature [15, $58,59,60]$.

\section{Construction of the multivariate regressions}

The selected model structure was a linear mixed-model (LMM) with the trap identifier as a random effect. Two approaches to building models were used: the backward stepwise approach and the forward stepwise approach [59]. The consistency between the two approaches was assessed. The variable selection process was carried out until all the explanatory variables in the models were significant, meaning they had a $p_{-}$value of less than or equal to 0.05 . Models without interactions and/or quadratic terms were designated as follow "LMMwithout". The number following the designation $(3,5$, or 10$)$ indicated the VIF threshold used. Next, the significance of the quadratic and interaction terms was tested for each of the variables retained in the multiple model. This approach was preferred to testing the quadratic and interaction effect together with univariate selection process because of the larger amount of predictive variables. Thus, when the relationship between a variable and the abundance of a species did not offer a strictly linear visual aspect, adding a quadratic or interaction term made it possible to better approximate the trend shown in the relationship. Quadratic and/or interaction terms were retained only if the original explanatory variable(s) and the term itself were significant. This second series of models was called the LMMwith model. We thus obtained six models that matched according to the backward stepwise and forward stepwise approaches, per species or group of species: three LMMwithout models for each VIF threshold and three LMMwith models for each of the three VIF thresholds.

Normality of residuals was checked using the Shapiro-Wilk, Anderson-Darling, Lilliefors and Jarque-Bera tests [60, 61], and their distribution was evaluated graphically using P-P and Q-Q plots. Homoscedasticity of Student residuals was evaluated graphically, as was their frequency distribution (which had to lie between -2 and +2 ). Student residuals were mapped in order to identify specific clusters or structures in the extreme values. Cook's distances were also calculated to identify outliers. The relevance of the six models per species or group of species was evaluated using Akaike's information criterion (AIC) [12, 14, 62]. The best or final model per species or group of species was the one that had the lowest AIC score. 
The expected values for 2014 were then calculated by the model and compared to the observed values, since these were the data chosen for validation by calculating raw and Student residuals. The same steps for residual analysis were carried out as described in the previous paragraph.

Most of the statistical operations were performed using the XLSTAT module [63] for Excel. To double-check the selection of variables, we redid the stepwise procedure in $\mathrm{R}$ version 3.4.2 [64].

\section{Mapping}

The Student residual values for the model calibration step and the external validation step (comparison with 2014 data) were spatially represented by categorizing the residuals as follows: "excellent" for an absolute value between 0 and 1; "very good" for a value between 1 and 2; "poor" for a value between 2 and 3 ; and "very poor" for a value between 3 and 4.5 .

With the purpose of comparing predicted and observed hot spot zones (for 2014), annual abundances for each of the four mosquito species or species groups were predicted for the entire study area for 2014 only (even though this could have been done for each year) using the validated LMM final models. As LMM models predicted Box-Cox transformed abundance of mosquito, we re-transformed the value to obtain true abundance. The abundance was classified inspired by Natural Breaks, in high, medium and low risk area, corresponding to high, medium and low mosquito abundance. The categories limits where different from one species to another. To map the models, the LCC variables were centered and reduced using the means and standard deviations of the training data. The LCC percentages and meteorological variables used in each model were calculated so that each pixel of the image received the average value of the surrounding pixels within a 1-km buffer.

\section{Results}

\section{Preparation of variables and univariate regression}

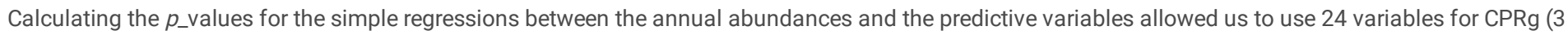
LCC and 21 meteorological), 39 for CQP (3 LCC and 36 meteorological), 38 for STMg (3 LCC and 35 meteorological) and 45 for VEX (2 LCC and 43 meteorological). By following the univariate selection process, these numbers dropped to 15 for CPRg, 22 for CQP, 20 for STMg and 25 for VEX. It was noted that all the LCC variables from univariate regressions were independent of each other.

Following the multicollinearity test conducted with VIF thresholds set to 3,5 and 10, there were no meteorological variables below the VIF threshold of 3 for any of the four species or species groups. To confirm whether adding meteorological variables improved the models, it was necessary to retain multiple models with thresholds equal to and greater than 3 . Table 3 shows the selected variables by VIF threshold and by species.

Table 3

Explanatory variables selected for modelling, following the multicollinearity test, with the direction of the association

\begin{tabular}{|c|c|c|c|}
\hline CPRg & CQP & STMg & VEX \\
\hline + Agri * & +Agri * & - Urban * & - Water * \\
\hline - Grassland * & - Urban ** & + Grassland * & + Agri * \\
\hline -Woodland * & + Woodland ** & +Woodland * & -Pfeb ** \\
\hline -TNsep_1y *** & +Pjan ** & -Pjan ** & -Psep_1y ** \\
\hline -Pmar *** & +Psep ** & + Pmar $* \star \star$ & +Pjan *** \\
\hline \multirow[t]{3}{*}{+ Paug $* \star \star$} & 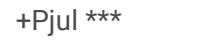 & 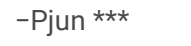 & 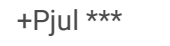 \\
\hline & 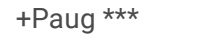 & 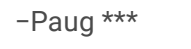 & +Psep *** \\
\hline & & 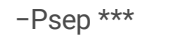 & \\
\hline
\end{tabular}

CPRg: Culex pipiens-restuans group; CQP: Coquillettidia perturbans; STMg: Ochlerotatus stimulans group; VEX: Aedes vexans; +: positive correlation; -: negative correlation; *: Variance inflation factor thresholds (VIF) $\leq 3,5$ and 10 ; **: VIF $\leq 5$ and 10 ; ***: VIF $\leq 10$

For CPRg, the VIF 3 and VIF 5 models were identical. In addition, only CPRg had a temperature variable in the VIF 10 model, namely the average minimum temperature in September of the previous year that was negatively correlated, in univariate analysis, with the annual abundances of CPRg. All other meteorological variables selected in the other models and for the other species were exclusively precipitation variables.

The meteorological variables associated with abundance were very different from one species to another. CQP and VEX appeared to be sensitive to winter (January precipitation), summer (July and August precipitation) and fall (September precipitation) conditions. CPRg abundances seemed to be affected more by spring (March) and summer (August) precipitation. As for STMg, all seasons seemed to be significant in terms of their mean precipitation.

For the LCCs, agricultural land appeared to have a predominant influence, since it was positively associated with CQP, VEX and CPRg. The urban LCC was negatively correlated with CQP and STMg, and the grassland and woodland LCCs were negatively correlated with CPRg and positively correlated with STMg. Lastly, for VEX only, water was negatively correlated.

\section{Construction of the multiple model}


CPRg: AIC scores were quite similar for the LMMwithout3 (AIC=651), LMMwithout10 (AIC=652) and LMMwith10 (AIC=651) models. However, with the goal being to assess the long-term impact of climate change and since the LMMwithout3 model did not include meteorological variables, we set it aside. The LMMwith10 model was selected as the final LMM model (Table 4). The mean annual abundance of CPRg was, therefore, predicted by a linear model combining three land cover variables (agricultural land, grassland and woodland), a climate variable (mean temperature in September of the previous year) and an interaction term combining the climate variable and woodland. The agricultural land LCC had a positive effect on the mean annual abundance of CPRg, while the grassland and woodland LCCs and the mean temperature in September of the previous year had a negative effect. The interaction effect between the woodland LCC and temperature balance this negative effect by making it stronger with negative value of mean temperature value and almost null for positive mean temperature value (see Suppl. 1). By comparing prediction for 2014 to the observed data for 2014, the frequency distribution of Student residuals looked like a normal distribution. Ninety-five point one per cent $(95.1 \%)$ of the values were between $[-2 ;+2]$. The mean was positive $(+0.602)$, meaning that the mean annual abundance values predicted by the model were generally higher than those actually observed.

CQP: No interaction or quadratic terms were significant in the models for CQP. LMMwithout10 had the lowest AIC score (AIC=530) (Table 4). The mean annual abundance of CQP was, therefore, predicted by a combination of two meteorological variables (mean precipitation in January and August) that had a positive effect on abundance and the percentage of urban land surrounding the trap, which had a negative effect on abundance. For CQP, the histogram of Student residuals showed a normal distribution with a mean of zero. Residual values were between -3.5 and +3 , with $94.6 \%$ of them falling in the [-2; +2$]$ range, thus the "excellent" class. By comparing the data simulated by the final model for 2014 to the observed data for 2014, the frequency distribution of Student residuals looked like a normal distribution. Ninety-six point six per cent of the values were between [-2;+2]. The mean was negative (-0.67), meaning that the mean annual abundance values predicted by the model were generally lower than those actually observed.

STMg LMMwith10 had the lowest AIC score (AIC=1013) (Table 4). The mean annual abundance of STMg was, therefore, predicted by a linear model combining two land cover variables (urban and woodland, the latter including a quadratic term) and a single meteorological variable (mean precipitation in June). The presence of urban land had a negative effect, as well as the mean precipitation in June. The effect of woodland has to be interpreted with caution combining the simple and the quadratic effect. It shows that abundance peaks at intermediate values of woodland cover, but that at too high or too low woodland densities, the environment is not favorable to STMg anymore (see Suppl. 1). For STMg, the histogram of Student residuals showed a normal distribution with a mean of zero. Residual values were between -3.5 and +3 , with $95.7 \%$ of them falling in the $[-2 ;+2]$ range. By comparing the data simulated by the final model for 2014 to the observed data for 2014, the frequency distribution of Student residuals looked like a normal distribution. One hundred per cent of the values were between $[-2 ;+2]$. The mean was negative $(-0.778)$, meaning that the mean annual abundance values predicted by the model were generally lower than those actually observed.

VEX LMMwith10 had the lowest AIC score (AIC=245) (Table 4). The mean annual abundance of VEX was, therefore, predicted by a linear model combining a land cover variable (agricultural land, in simple and quadratic form) and three climate variables (mean precipitation in January, February and September of the current year, and the interaction between January and September precipitation). The agricultural land LCC, because combining a single and a quadratic term, had a positive effect on the abundance of VEX only in an intermediate agricultural LCC density (see Suppl.1). Below and above this intermediate density, the agricultural land LCC becomes less favorable to VEX. January and September precipitation had a positive effect on VEX abundance, that is more important for the lowest September mean annual precipitation, because of their interaction term. February precipitation had a negative effect. For VEX, the histogram of Student residuals showed a normal distribution with a mean of zero. Residual values were between -3 and +2.5 , with $94 \%$ of them falling in the [-2; +2$]$ range. By comparing the data simulated by the final model for 2014 to the observed data for 2014, the frequency distribution of Student residuals looked like a normal distribution. Ninety-six point one per cent $(96.1 \%)$ of the values were between $[-2 ;+2]$. The mean was negative $(-0.57)$, meaning that the mean annual abundance values predicted by the model were generally lower than those actually observed.

For the four species, the Q-Q and P-P plots of the raw residuals confirmed that their distributions were near normal. The Student residuals were well distributed and did not appear to have a specific structure, thus supporting the normality assumption for raw residuals and the homoscedasticity assumption for Student residuals, as required to validate a linear model. Similarly, the Cook's distances confirmed the good results obtained with the Student residuals histograms. Distances were all less than 0.1 for all species or species groups except CPRg, which had a single value slightly greater than 0.15 (trap OKA 007 0).

Table 4: Final models for the variance inflation factor threshold of 10 


\begin{tabular}{|c|c|c|c|c|c|c|c|}
\hline Source & Value & SE & DF & $\mathrm{t}$ & $\operatorname{Pr}>|t|$ & LL (95\%) & UL (95\%) \\
\hline \multicolumn{8}{|c|}{ Culex pipiens-restuans group (CPRg) } \\
\hline Intercept & 6.369 & 0.117 & 57 & 54.415 & $<0.0001$ & 6.139 & 6.600 \\
\hline Agri & 0.658 & 0.121 & 57 & 5.455 & $<0.0001$ & 0.420 & 0.896 \\
\hline Grassland & -0.422 & 0.121 & 57 & -3.473 & 0.001 & -0.662 & -0.182 \\
\hline Woodland & -0.256 & 0.128 & 57 & -2.007 & 0.050 & -0.507 & -0.004 \\
\hline TNsep_1y & -0.218 & 0.103 & 57 & -2.103 & 0.040 & -0.422 & -0.013 \\
\hline Woodland×TNsep_1y & 0.239 & 0.102 & 57 & 2.342 & 0.023 & 0.038 & 0.441 \\
\hline \multicolumn{8}{|c|}{ Coquillettidia perturbans (CQP) } \\
\hline Intercept & 3.700 & 0.091 & 59 & 40.693 & $<0.0001$ & 3.521 & 3.879 \\
\hline Urban & -0.535 & 0.090 & 59 & -5.947 & $<0.0001$ & -0.713 & -0.358 \\
\hline Pjan & 0.244 & 0.062 & 59 & 3.904 & 0.000 & 0.121 & 0.367 \\
\hline Paug & 0.265 & 0.070 & 59 & 3.769 & 0.000 & 0.126 & 0.403 \\
\hline \multicolumn{8}{|c|}{ Ochlerotatus stimulans group (STMg) } \\
\hline Intercept & 6.533 & 0.331 & 58 & 19.715 & $<0.0001$ & 5.879 & 7.187 \\
\hline Urban & -1.448 & 0.467 & 58 & -3.103 & 0.003 & -2.369 & -0.527 \\
\hline Woodland & 1.907 & 0.604 & 58 & 3.155 & 0.003 & 0.714 & 3.099 \\
\hline Pjun & -1.127 & 0.240 & 58 & -4.693 & $<0.0001$ & -1.601 & -0.653 \\
\hline Woodland $\times$ Woodland & -1.146 & 0.507 & 58 & -2.260 & 0.028 & -2.147 & -0.146 \\
\hline \multicolumn{8}{|l|}{ Aedes vexans (VEX) } \\
\hline Intercept & 4.615 & 0.035 & 56 & 132.824 & $<0.0001$ & 4.546 & 4.683 \\
\hline Agri & 0.256 & 0.071 & 56 & 3.584 & 0.001 & 0.115 & 0.396 \\
\hline Pfeb & -0.126 & 0.037 & 56 & -3.440 & 0.001 & -0.198 & -0.054 \\
\hline Pjan & 0.227 & 0.036 & 56 & 6.344 & $<0.0001$ & 0.156 & 0.297 \\
\hline Psep & 0.126 & 0.032 & 56 & 3.902 & 0.000 & 0.062 & 0.190 \\
\hline Agri×Agri & -0.158 & 0.069 & 56 & -2.294 & 0.026 & -0.294 & -0.022 \\
\hline Pjan×Psep & 0.159 & 0.039 & 56 & 4.091 & 0.000 & 0.082 & 0.236 \\
\hline
\end{tabular}

SE: Standard error; DF: Degree of freedom; LL: Lower limit; UL: Upper limit

\section{Mapping}

\section{Mapping of residuals}

For all species, the calibration residual values were spread across the region without any particular clustering. The residuals from the external validation showed the same lack of spatial pattern, except for a cluster of negative values around the Marguerite-D'Youville wildlife refuge $\left(45^{\circ} 385 \mathrm{~N}, 73^{\circ} 77 \mathrm{~W}\right)$ : the observed values from traps were higher than those predicted (Fig. 2, 3, 4, 5), including for the CPRg model, which generally overestimated abundances.

\section{Mapping of mean annual abundance for the entire study area}

The maps allow us to observe that the hot spots on the maps overlap with the highest mosquito abundances observed in 2014, in general. Additionally, outside of the calibrated area (where colors are lighter), the prediction are more difficult to interpret and probably less reliable in terms of mosquito abundance prediction.

CPRg: The predictive map for 2014 shows some homogeneity on the island of Montreal, with some highly localized hot spots, shown in red. Outside the island of Montreal, there is more variability, with some hot spots located in densely wooded areas. However, the regression coefficient for this variable is negative, meaning that the "September temperature $\times$ woodland" interaction term attenuates the simple "woodland" variable. Intermediate abundances are mainly associated with the presence of agricultural plots. The few cold spots can be explained by the presence of grasslands, which have a negative influence in the regression model, or, further north in the study area, by drastically cooler temperatures in September, or by high densities of woodland. 
CQP: High abundances of CQP are associated with less urbanized areas, which is consistent with the value of the coefficient associated with this variable in the final model (Fig. 7). The more subtle variations in abundance can be explained by the two precipitation variables. The observational data for 2014 blend generally very well with the simulated data, which highlights the accuracy and precision of the model.

STMg: There is a lower abundance of this group of species in urbanized areas compared to woodlands where there's a higher abundance (Fig. 8). High risk areas are mostly associated with rapidly increasing abundance near woodlands.

VEX: The predicted abundances show a very rapid variation at the edge of agricultural areas (Fig. 9). For this variable, Temperature differences probably explain the more subtle additional variations.

\section{Discussion}

This paper led to the creation of maps of mean annual abundance for four mosquito species or species groups that are key to public health, for southern Quebec. Validation of the model with external data (year 2014) established the robustness of the model and effectiveness of the method used.

Predictive mapping for CPRg is based on the agricultural land, grassland and woodland LCCs, the mean minimum temperatures in September of the previous year, and the interaction between these temperatures and the woodland LCC. While this group of mosquitoes is known to be very prevalent in urban areas [26, 65], other authors have demonstrated the impacts of other agricultural land, woodland or grassland cover variables on the occurrence of CPR [21, 25]. These publications show that agricultural land cover has a positive impact and dense woodland cover has a negative impact, which is consistent with our results. Many models that predict CPR abundance do not use LCCs as predictive variables, but only meteorological variables [11, 44, 66], so it is difficult to compare their results to our work. Moreover, some of these authors highlight the importance of adding environmental factors to improve the accuracy of their predictions [44].

Studies on VEX habitats indicate that this species develops mainly in temporary pools of water caused by recent flooding or precipitation [19, 67]. These pools and other puddles may be located on agricultural land [31], woodland, grassland [25, 32,33] or pastures [32, 33]. This is partly consistent with our results showing that agricultural land has a positive influence on VEX abundance in conjunction with winter and fall precipitation. Little statistical modelling work has been done on VEX in Canada. The only existing work is that of Ripoche [44], and it uses only meteorological variables as predictive variables. Therefore, our results cannot be compared to theirs.

Regarding STMg, we found that it is rather positively influenced by the presence of wooded areas and negatively influenced by the presence of urban areas. This result is consistent with the scarce empirical information in the literature that describes this group as mosquito species that seek vernal pools, which seem more common in wooded areas than in urban areas $[39,40,67]$, and whose larval habitat seems to be located in depressions in wooded areas in the case of Oc. stimulans [67], and in flooded herbaceous areas in the case of Oc. hexodontus [68]. However, the geographic range of the latter species appears to be limited to an area much farther north than our study area [69], suggesting that the STM species group in our study may in fact consist exclusively of the Oc. Stimulans species.

It is also difficult to compare our results for the species CQP to the literature, because work on this species is scarce. According to Crans [67], CQP eggs are deposited directly on water. According to Gardner [25], who captured adult CQP with CDC light traps like ours, this species was trapped primarily in prairie, forest, and agricultural sites, and, to a lesser extent, in residential sites. This information is consistent with our results, which show that the only LCC variable that influences CQP abundance is urban land, with a negative relationship. This makes our work a valuable tool for providing information on the environmental conditions of choice for CQP in Quebec.

The abundance maps predicted by our models show great heterogeneity between urban and peri-urban areas in terms of predicted abundances for all species, even VEX and those in the CPR group, for which the urban LCC variable was not included in the model. This can be explained by the fact that the traps used to produce our data were all in urban areas; therefore, the effect of this type of cover was modelled quite sensitively with our data. Moreover, the satellite data available to characterize our LCCs were available only from 2011 onward. However, the landscape changed between 2003 and 2011 (period covering the mosquito trapping data we worked with), especially in terms of urban land, which has expanded significantly in recent years in our study area. This factor must have played in favour of the underestimation of the impact of urban areas on mosquito abundances and, therefore, on the precision of the model in discriminating the spatial heterogeneity of abundances between urban and non-urban areas. For similar work, we recommend, whenever possible, the use of multi-temporal data that have a resolution of $30 \mathrm{~m}$ or less and can provide a detailed classification of the region, as we have demonstrated the importance of using LCC variables as much as meteorological data in mosquito abundance modelling work.

In addition to successfully modelling mean annual abundances for four different species, we have undertaken work on species that are scarcely studied despite being potential vectors of several viruses transmissible to humans. Many studies focus on the CPR group [11, 17, 26, 42, 70], or on both CPR and VEX [44] because of their potential to transmit West Nile virus, which is the most widespread arbovirus in Canada. Our selection of species studied includes a fortiori potential vectors for other diseases that are rarer but as present in Canada as WNV: CQP for EEE and STMg for California serogroup viruses [5]. This paper shows that it is possible to work on other, sometimes ignored, species of mosquitoes that pose a public health risk, using a robust and easily reproducible approach.

The modelling could have taken other effects into account, such as larviciding [44, 70]. Although these effects are controversial in other studies, particularly for the CPR group [71], the results we obtained in the vicinity of the Île Saint-Bernard wildlife refuge-whose purpose of preserving wildlife and plant life could be why larviciding is restricted there-suggest that adding a variable describing the presence of larvicide treatment to our models would make them more precise for this area, where it appears that they systematically underestimate the observed abundance values. 
Given the nature of our meteorological data, and while our results are very encouraging, we recommend refining the precision of the meteorological variables using microclimatic data, in order to more accurately capture intra-seasonal and spatial variations in abundance. In addition, this would make it possible to test new explanatory variables, such as wind $[11,72,73]$ or relative humidity [74], all of which are meteorological variables influencing the biology and dispersion of mosquitoes.

\section{Conclusions}

The method presented in this paper to map mean annual abundances for various mosquito species in southern Quebec is a first step toward developing a practical tool that can be used in decision making to identify areas of risk of exposure to infected mosquitoes. Indeed, no method had yet been developed in this study area to be applicable on a large scale and on four distinct species. The simplicity of the method used and the use of relatively generic LCC and climate variables are encouraging.

This type of model can also help to study the impact of climate and environmental change on the distribution of these mosquito species in time and space from a public health perspective. Indeed, temperature, precipitation and the presence of urban areas are very important variables in our models and are undergoing profound changes: we note growing urban consumption of land, in tandem with an increase in mean temperatures and a change in precipitation patterns [75]. These three major effects can, therefore, be expected to significantly alter the landscape of mosquito abundances in the coming years and, consequently, the risk of exposure to mosquito-borne diseases.

\section{List Of Abbreviations}

_1y: From previous year; AAFC: Agriculture and Agri-Food Canada; Agri : Agricultural; AIC: Akaike Information Criterion; An: Annual; CDC: Center for Disease Control; CPRg: Culex pipiens-restuans group; CQP: Coquillettidia perturbans; CSG: Californian Serogroup; CVV: Cache Valley Virus; DUC: Duck Unlimitted Canada; EEE: Eastern Equine Encephalitis virus; GoC: Government of Canada; INSPQ: Institut national de santé publique du Québec; JCV: Jamestown Canyon Virus; LCC: Land cover class; LMM: Linear mixed model; MSSS: Ministère de la santé et des services sociaux; NHN: National Hydrographic Network; P: Mean precipitation; PHAC: Public Health Agency of Canada; SLEV: St.Louis Encephalitis Virus; SMTg: Ochlerotatus stimulans group; SSHV : Snowshoe Hare Virus; TN: Minimal temperature; TX: Maximal temperature; TY: Mean temperature; VEX: Aedes vexans; VIF: Variance Influence Factor; WL: Wetlands; WNV: West Nile virus

\section{Declarations}

\section{Acknowledgements and funding}

We wish to thank the Public Health Agency of Canada and the MITACS Fund for funding this study and awarding a master's fellowship, the Institut national de santé publique du Québec (Alejandra Irace-Cima) and Quebec's Ministère de la Santé et des Services sociaux for sharing entomological surveillance data from the provincial West Nile virus surveillance program, and GDG Environnement for sharing some of their mosquito sampling data for southern Quebec.

\section{Ethics approval and consent to participate}

Not applicable.

\section{Consent for publication}

All authors read and approved the final manuscript.

\section{Availability of data and materials}

The data that support the findings of this study are available from the Institut national de santé publique du Québec and GDG Environnement but restrictions apply to the availability of these data, which were used under license for the current study, and so are not publicly available.

\section{Competing interests}

The authors declare that they have no competing interests.

\section{Authors' contributions}

AL and SOK oversaw the research design, assisted by RF. SOK programmed and ran all the data preprocessing. JA conducted the literature review, processed data and ran the statistical and geographical analysis. AL provided the entomological methodology and material. FR provided statistics methodology and contributed material on statistics. AL and SOK contributed to draft and edit the manuscript assisted by JA. FR and RF contributed to edit it. All authors read and approved the final manuscript.

\section{References}

1. Public Health Agency of Canada. Surveillance of West Nile virus. 2019. https://www.canada.ca/en/public-health/services/diseases/west-nilevirus/surveillance-west-nile-virus.html 
2. Government of Canada. Surveillance of West Nile virus in Government of Canada, Ottawa. 2018. https://www.canada.ca/en/publichealth/services/diseases/west-nile-virus/surveillance-west-nile-virus.html

3. Public Health Agency of Canada. West Nile Virus and Other Mosquito-borne Disease National Surveillance Rep. 2016 Rep. https://www.canada.ca/en/public-health/services/publications/diseases-conditions/west-nile-virus-other-mosquito-borne-disease-national-surveillancereport-2016-final-summary.html

4. Drebot M. Emerging mosquito-borne bunyaviruses in Canada. Canada Communicable Disease Rep. (CCDR) 2015;41(6):117-123. https://dx.doi.org/10.14745\%2Fccdr.v41i06a01

5. Ludwig A, Zheng H, Vrbova L, Drebot MA, Iranpour M, Lindsay LR. Increased risk of endemic mosquito-borne diseases in Canada due to climate change. Canada Communicable Disease Rep. 2019;45(4):90-97. https://www.canada.ca/en/public-health/services/reports-publications/canada-communicabledisease-report-ccdr/monthly-issue/2019-45/issue-4-april-4-2019/article-3-endemic-mosquito-borne-diseases-climate-change.html

6. Ministère de la Santé et des Services sociaux du Québec in Gouvernement du Québec, Quebec. 2019.

http://www.msss.gouv.qc.ca/professionnels/zoonoses/virus-du-nil-occidental-vno/tableau-des-cas-humains-vno-bilan

7. Ministère de la Santé et des Services sociaux du Québec in Gouvernement du Québec, Quebec. 2019.

http://www.msss.gouv.qc.ca/professionnels/zoonoses/surveillance-des-maladies-d-interet-transmises-par-des-moustiques-au-quebec/encephaliteequine-de-l-est/

8. Ministère de la Santé et des Services sociaux du Québec in Gouvernement du Québec, Quebec. 2019.

http://www.msss.gouv.qc.ca/professionnels/zoonoses/surveillance-des-maladies-d-interet-transmises-par-des-moustiques-au-quebec/les-virus-duserogroupe-californie/

9. Ministère de la Santé et des Services sociaux du Québec. Surveillance des maladies d'intérêt transmises par des moustiques au Québec in Gouvernement du Québec, Quebec. 2018. http://www.msss.gouv.qc.ca/professionnels/zoonoses/surveillance-des-maladies-d-interet-transmises-par-des-moustiques-auquebec/.

10. Bouden M, Moulin B, Gosselin P. The geosimulation of West Nile virus propagation: a multi-agent and climate sensitive tool for risk management in public health. Int J Health Geogr. 2008;7(1):1. https://doi.org/10.1186/1476-072X-7-35

11. Lebl K, Brugger K, Rubel F. Predicting Culex pipiens/restuans population dynamics by interval lagged weather data. Parasites \& Vectors. $2013 ; 6(1): 1$. https://doi.org/10.1186/1756-3305-6-129

12. Rochlin I, Turbow D, Gomez F, Ninivaggi DV, Campbell SR. Predictive Mapping of Human Risk for West Nile Virus (WNV) Based on Env Socioeconomic Factors. PLoS ONE. 2011; 6(8):e23280. https://doi.org/10.1371/journal.pone.0023280

13. Yoo EH. Site-specific prediction of West Nile virus mosquito abundance in Greater Toronto Area using generalized linear mixed models. Int J Geogr. Inform Science. 2014;28(2):296-313. https://doi.org/10.1080/13658816.2013.837909

14. Chen CC, Epp T, Jenkins E, Waldner C, Curry PS, Soos C. Modeling Monthly Variation of Culex tarsalis (Diptera: Culicidae) Abundance and West Nile Virus Infection Rate in the Canadian Prairies. Int J Env Research Public Health. 2013;10(7):3033-3051. https://doi.org/10.3390/ijerph10073033

15. Cleckner HL, Allen TR, Bellows AS. Remote Sensing and Modeling of Mosquito Abundance and Habitats in Coastal Virginia, USA. Remote Sensing. 2011;3(12):2663-2681. https://doi.org/10.3390/rs3122663

16. El Adlouni S, Beaulieu C, Ouarda TB, Gosselin PL, Saint-Hilaire A. Effects of climate on West Nile Virus transmission risk used for public health decisionmaking in Quebec. Int J Health Geogr. 2007;6(1):40. https://doi.org/10.1186/1476-072X-6-40

17. Jacob BG, Gu W, Caamano EX, Novak RJ. Developing operational algorithms using linear and non-linear squares estimation in Python ${ }^{8}$ for the identification of Culex pipiens and Culex restuans in a mosquito abatement district (Cook County, Illinois, USA). Geosp Health. 2009;3(2):157-176. http://eprints.bice.rm.cnr.it/2868/

18. Liu H, Weng Q. Enhancing temporal resolution of satellite imagery for public health studies: A case study of West Nile Virus outbreak in Los Angeles in 2007. Remote Sensing Env. 2012;117:57-71. https://doi.org/10.1016/j.rse.2011.06.023

19. Trawinski PR, Mackay DS. Spatial autocorrelation of West Nile virus vector mosquito abundance in a seasonally wet suburban environment. J Geogr Systems. 2009;11(1):67-87. https://doi.org/10.1007/s10109-008-0070-8

20. Wang X, Wang J, Russell C, Proctor P, Bello R, Higuchi K, Zhu H. Clustering of the abundance of West Nile virus vector mosquitoes in Peel Region, Ontario, Canada. Env Ecol Stats. 2014;21(4):651-666. https://doi.org/10.1007/s10651-014-0273-8

21. Trawinski PR, Mackay DS. Identification of Environmental Covariates of West Nile Virus Vector Mosquito Population Abundance. Vector-Borne \& Zoonotic Diseases. 2010;10(5):515-526. https://doi.org/10.1089/vbz.2008.0063

22. Reisen WK. Ecology of West Nile Virus in North America. Viruses. 2013;5.

23. Andreadis TG, Anderson JF, Tirrell-Peck SJ. Multiple Isolations of Eastern Equine Encephalitis and Highlands J Viruses from Mosquitoes (Diptera: Culicidae) During a 1996 Epizootic in Southeastern Connecticut. J Med Entomology. 1998;35(3):296-302. https://doi.org/10.1093/jmedent/35.3.296

24. Srihongse S, Woodall JP, Grayson MA, Deibel R, Bast TF, Morris CD, Bosler EM, Benach JL, Howard JJ, Berlin J. Arboviruses in New York State: surveillance in arthropods and nonhuman vertebrates, 1972-1977. Mosquito News. 1980;40(2):269-276. http://pascal-francis.inist.fr/vibad/index.php? action=getRecordDetail\&idt=PASCALZOOLINEINRA8110225962

25. Gardner AM, Lampman RL, Muturi EJ. Land Use Patterns and the Risk of West Nile Virus Transmission in Central Illinois. Vector-Borne \& Zoonotic Diseases. 2014;14(5):338-345. https://doi.org/10.1089/vbz.2013.1477

26. Jacob BG, Lampman RL, Ward MP, Muturi EJ, Morris JA, Caamano EX, Novak RJ. Geospatial variability in the egg raft distribution and abundance of Culex pipiens and Culex restuans in Urbana-Champaign, Illinois. Int J Remote Sensing. 2009;30(8):2005-2019.

Page $11 / 20$ 
https://doi.org/10.1080/01431160802549195

27. Turell MJ, Sardelis MR, Dohm DJ, O'Guinn ML. Potential North American Vectors of West Nile Virus. Annals of the New York Academy of Sciences. 2001;951(1):317-324. https://doi.org/10.1111/j.1749-6632.2001.tb02707.x

28. Anderson JF, Main AJ, Armstrong PM, Andreadis TG, Ferrandino FJ. Arboviruses in North Dakota, 2003-2006. American J Tropical Med \& Hygiene 2015;92(2):377-393. https://doi.org/10.4269/ajtmh.14-0291

29. Goddard LB, Roth AE, Reisen WK, Scott TW. Vector Competence of California mosquitoes for West Nile virus. Emerging Infectious Diseases. 2002;8(12):1385. https://dx.doi.org/10.3201\%2Feid0812.020536

30. Main AJ, Brown SE, Wallis RC, Elston J. Arbovirus surveillance in Connecticut. II. California serogroup [Aedes species, insect vectors]. Mosquito News. 1979;39(3):552-559. http://pascal-francis.inist.fr/vibad/index.php?action=getRecordDetail\&idt=PASCAL8050389947

31. Rocheleau JP. Les caractéristiques environnementales du risque d'exposition aux arbovirus au Québec. Doctoral dissertation. Faculty of Veterinary Medicine, Université de Montréal, Canada. 2016. http://hdl.handle.net/1866/18325

32. Strickman D. Stimuli affecting selection of oviposition sites by Aedes vexans (Diptera: Culicidae): moisture. Mosquito News. 1980;40(2):236-245. https://www.biodiversitylibrary.org/content/part/JAMCA/MN_V40_N2_P236-245.pdf

33. Strickman D. Stimuli Affecting Selection of Oviposition Sites by Aedes Vexans (Diptera: Culicidae): Light. J Med Entomology. 1982;19(2):181-184. https://doi.org/10.1093/jmedent/19.2.181

34. Bosak PJ, Crans WJ. The structure and function of the larval siphon and spiracular apparatus of Coquillettidia perturbans. J of the American Mosquito Control Association - Mosquito News. 2002;18(4):280-283. https://www.biodiversitylibrary.org/content/part/JAMCA/JAMCA_V18_N4_P280-283.pdf

35. Andreadis TG, Anderson JF, Armstrong PM, Main AJ. Isolations of Jamestown Canyon Virus (Bunyaviridae: Orthobunyavirus) from Field-Collected Mosquitoes (Diptera: Culicidae) in Connecticut, USA: A Ten-Year Analysis, 1997-2006. Vector-Borne \& Zoonotic Diseases. 2008;8(2):175-188. https://doi.org/10.1089/vbz.2007.0169

36. Walker ED, Grayson MA, Edman JD. Isolation of Jamestown Canyon and Snowshoe Hare Viruses (California Serogroup) from Aedes Mosquitoes in Western Massachusetts. J American Mosquito Control Association. 1993;9(2):131-134. https://www.biodiversitylibrary.org/content/part/JAMCA/JAMCA_V09_N2_P131-134.pdf

37. Murdock CC, Olival KJ, Perkins SL. Molecular Identification of Host Feeding Patterns of Snow-Melt Mosquitoes (Diptera: Culicidae): Potential Implications for the Transmission Ecology of Jamestown Canyon Virus. J Med Entomology. 2014;47(2):226-229. https://doi.org/10.1093/jmedent/47.2.226

38. Wagner RJ, DeJong C, Leung MK, McLintock J, Iversen JO. Isolations of California encephalitis virus from tundra mosquitoes. Canadian J Microbiology. 1975;21(4):574-576. https://doi.org/10.1139/m75-081

39. Maire A, Aubin A. Les moustiques du Québec (Diptera : Culicidae). Essai de synthèse écologique. Mémoires de la société entomologique du Québec. 1980;6:107. https://search.library.utoronto.ca/details?2636318\&uuid=3d245824-eebc-40ca-8bbc-f784ffe46e82

40. Wood DM, Dang PT, Ellis RA. The insects and arachnids of Canada. Part 6. The mosquitoes of Canada. (Diptera: Culicidae). Canadian Government Publishing Centre. 1979;390 p. https://www.cabdirect.org/cabdirect/abstract/19800579190

41. Clements AN. The biology of mosquitoes: sensory reception and behaviour, Wallingford: CABI Publishing. 1999;2:740 p. https://doi.org/10.1017/S0007485300000171

42. Edillo F, Kiszewski A, Manjourides J, Pagano M, Hutchinson M, Kyle A, Arias J, Gaines D, Lampman R, Novak R, Foppa I, Lubelcyzk C, Smith R, Moncayo A, Spielman A, and The Culex pipiens Working Group. Effects of Latitude and Longitude on the Population Structure of Culex pipiens s.l., Vectors of West Nile Virus in North America. American J Tropical Med \& Hygiene. 2009;81(5):842-848. https://doi.org/10.4269/ajtmh.2009.08-0605

43. Ozdenerol E, Bialkowska-Jelinska E, Taff GN. Locating suitable habitats for West Nile Virus-infected mosquitoes through association of environmental characteristics with infected mosquito locations: a case study in Shelby County, Tennessee. Int J Health Geogr. 2008;7(1):1.

https://doi.org/10.1186/1476-072X-7-12

44. Ripoche M, Campagna C, Ludwig A, Ogden NH, Leighton PA. Short-term Forecasting of Daily Abundance of West Nile Virus Vectors Culex pipiens-restuans (Diptera: Culicidae) and Aedes vexans Based on Weather Conditions in Southern Québec (Canada). J Med Entomology. 2019;56(3):859-872. https://doi.org/10.1093/jme/tjz002

45. Wang G, Minnis RB, Belant JL, Wax CL. Dry weather induces outbreaks of human West Nile virus infections. BMC Infectious Diseases. $2010 ; 10(1): 1$. https://doi.org/10.1186/1471-2334-10-38

46. Wimberly MC, Lamsal A, Giacomo P, Chuang TW. Regional Variation of Climatic Influences on West Nile Virus Outbreaks in the United States. American J Tropical Med \& Hygiene. 2014;91(4):677-684. https://doi.org/10.4269/ajtmh.14-0239

47. Pritchard EJ, Lewis DJ, Rau ME. Seasonal abundance and distribution of mosquito species (Culicidae) in southwestern Québec and their potential role as vectors of West Nile Virus (Doctoral dissertation, McGill University). 2010:174 p.

48. Köppen-Geiger. World Map of the Köppen-Geiger Climate Classification Updated in World maps of Köppen-Geiger climate classification. 2019. http://dx.doi.org/10.1127/0941-2948/2006/0130

49. Giordano BV, Gasparotto A, Hunter FF. A Checklist of the 67 Mosquito Species of Ontario, Canada. J American Mosquito Control Association. 2015;31(1):101-103. https://doi.org/10.2987/14-6456R.1

50. Agriculture and Agri-Food Canada. ISO 19131 AAFC Annual Crop Inventory - Data Product Specifications - Revision A. $2019: 26$ p. http://www.agr.gc.ca/atlas/supportdocument_documentdesupport/annualCroplnventory/en/ISO\%2019131_AAFC_Annual_Crop_Inventory_Data_Product_:

51. Government of Canada. Land Cover in Government of Canada, Ottawa. 2019. https://open.canada.ca/data/en/dataset/d1fc6010-e2e7-401a-8dc1$544 c d 2 a c 0 b 03$

Page $12 / 20$ 
52. Ducks Unlimited. Our Work / Impact Area - Wetlands in Ducks Unlimited Canada, Conserving Canada's Wetlands, Stonewall, Manitoba, Canada. 2018. https://www.ducks.ca/our-work/wetlands/

53. Government of Canada. Land Cover in Government of Canada, Ottawa. 2019. https://www.nrcan.gc.ca/science-and-data/science-and-research/earthsciences/geography/topographic-information/geobase-surface-water-program-geeau/national-hydrographic-network/21361

54. PCI Geomatics, Geomatica: Markham, Ontario, Canada. 2019. https://www.pcigeomatics.com/

55. Esri. ArcGIS Desktop: Release 10.6. Environmental Systems Research Institute. Redlands, California, United States. 2019. http://desktop.arcgis.com/en/

56. Government of Canada. Historical Data. in Government of Canada, Ottawa. 2018.

https://climate.weather.gc.ca/historical_data/search_historic_data_e.html

57. Ruiz MO, Chaves LF, Hamer GL, Sun T, Brown WM, Walker ED, Haramis L, Goldberg TL, Kitron UD. Local impact of temperature and precipitation on West Nile virus infection in Culex species mosquitoes in northeast Illinois, USA. Parasites \& Vectors. 2010;3(1):19. https://doi.org/10.1186/1756-3305-3-19

58. Brunkard JM, López JLR, Ramirez J, Cifuentes E, Rothenberg SJ, Hunsperger EA, Moore CG, Brussolo RM, Villarreal NA, Haddad BM. Dengue Fever Seroprevalence and Risk Factors, Texas-Mexico Border, 2004. Emerging Infectious Diseases. 2007;13(10):1477.

https://dx.doi.org/10.3201\%2Feid1310.061586

59. Dohoo IR, Martin W, Stryhn H. Veterinary Epidemiologic Research, 2nd Edition. Charlottetown, Canada: AVC Incorporated. 2003. http://projects.upei.ca/ver/

60. Zuur AF, leno EN, Elphick CS. A protocol for data exploration to avoid common statistical problems. Methods in Ecology \& Evolution. 2010;1(1):3-14. https://doi.org/10.1111/j.2041-210X.2009.00001.x

61. Wajnberg E. Introduction au Modèle Linéaire Généralisé (Generalized Linear Model ; GML). Course UE7. Université de Nice-Sophia-Antipolis. 2011. http://sites.unice.fr/coquillard/UE7/cours\%20IV\%20\%28GLM\%201\%29.pdf

62. Schurich JA, Kumar S, Eisen L, Moore CG. Modeling Culex tarsalis Abundance on the Northern Colorado Front Range Using a Landscape-Level Approach. J American Mosquito Control Association. 2014;30(1):7-20. https://doi.org/10.2987/13-6373.1

63. Addinsoft XLSTAT 2019: Data Analysis and Statistical Solution for Microsoft Excel. Paris, France. 2019. https://www.xlstat.com/en/

64. Yoo EH, Chen D, Diao C, Russell C. The Effects of Weather and Environmental Factors on West Nile Virus Mosquito Abundance in Greater Toronto Area. Earth Interactions. 2016;20(3):1-22. https://doi.org/10.1175/El-D-15-0003.1

65. Hongoh V, Berrang-Ford L, Scott ME, Lindsay LR. Expanding geographical distribution of the mosquito, Culex pipiens, in Canada under climate change. Applied Geogr. 2012;33:53-62. https://doi.org/10.1016/j.apgeog.2011.05.015

66. Crans WJ. A classification system for mosquito life cycles: life cycle types for mosquitoes of the northeastern United States. J Vector Ecology. 2004;29(1):1-10. http://vectorbio.rutgers.edu/outreach/mosclassSOVE.php

67. Albers MA, Bradley TJ. On the Evolution of Saline Tolerance in the Larvae of Mosquitoes in the Genus Ochlerotatus. Physiological and Biochemical Zoology. 2011;84(3):258-267. https://doi.org/10.1086/659769

69. Ward RD, Darsie RF. Identification and Geographical Distribution of the Mosquitoes of North America, North of Mexico. University Press of Florida, USA. 2005:416 p.

70. Wang J, Ogden NH, Zhu H. The Impact of Weather Conditions on Culex pipiens and Culex restuans (Diptera: Culicidae) Abundance: A Case Study in Peel Region. J Med Entomology. 2011;48(2):468-475. https://doi.org/10.1603/ME10117

71. Bodner D, LaDeau SL, Leisnham, PT. Relationships Among Immature-Stage Metrics and Adult Abundances of Mosquito Populations in Baltimore, MD. J Med Entomology. 2018;56(1):192-198. https://doi.org/10.1093/jme/tjy185

72. Hamer GL, Anderson TK, Donovan DJ, Brawn JD, Krebs BL, Gardner AM, Ruiz MO, Brown WM, Kitron UD, Newman CM, Goldberg TL, Walker ED. Dispersal of Adult Culex Mosquitoes in an Urban West Nile virus Hotspot: A Mark-Capture Study Incorporating Stable Isotope Enrichment of Natural Larval Habitats. PLoS Neglected Tropical Diseases. 2014;8(3):1-7. https://doi.org/10.1371/journal.pntd.0002768

73. Karki S, Hamer GL, Anderson TK, Goldberg TL, Kitron UD, Krebs BL, Walker ED, Ruiz MO. Effect of Trapping Methods, Weather, and Landscape on Estimates of the Culex Vector Mosquito Abundance. Env Health Insights. 2016;10:93-103.EHI-S33384. https://doi.org/10.4137/EHI.S33384

74. Platt RB, Love GJ, Williams EL. A Positive Correlation Between Relative Humidity and the Distribution and Abundance of Aedes Vexans. Ecology. 1958;39(1):167-169. doi:10.2307/1929987 https://www.jstor.org/stable/1929987

75. Ogden NH, Gachon P. Climate change and infectious diseases: What can we expect? Canada Communicable Disease Rep. 2019;45(4).

\section{Figures}




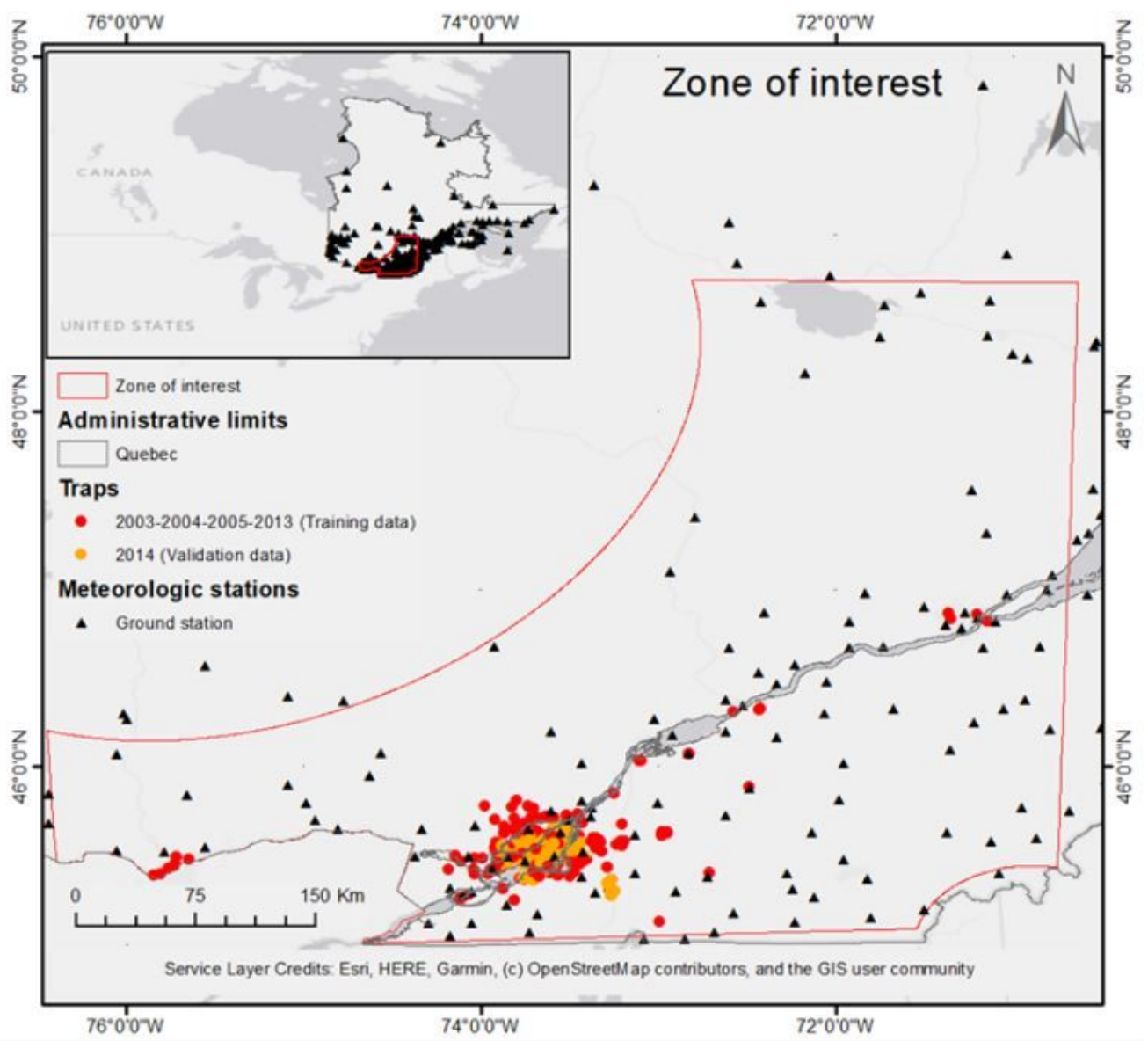

Figure 1

Study area (red border) located in southern Quebec. Entomological data for 2003, 2004, 2005 and 2013 are represented by red dots, and data for 2014 by orange dots (no data outside the Montreal region). Black triangles represent Environment and Climate Change Canada meteorological stations. 


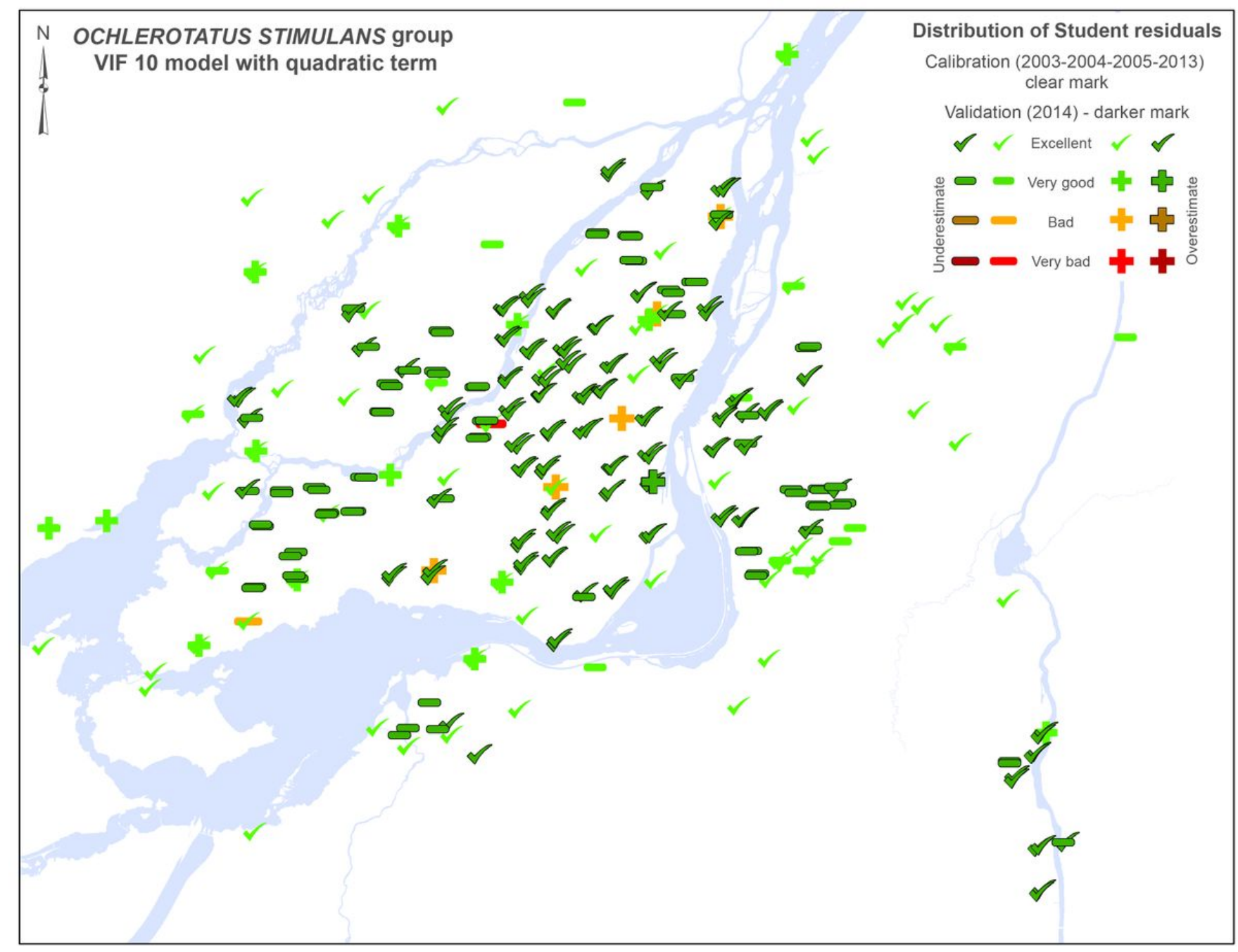

\section{Figure 2}

Distribution of Student residuals for the LMMwith10 model for the Ochlerotatus stimulans group for the region of our study area with the majority of the entomological data including 2014 data (our validation dataset). 


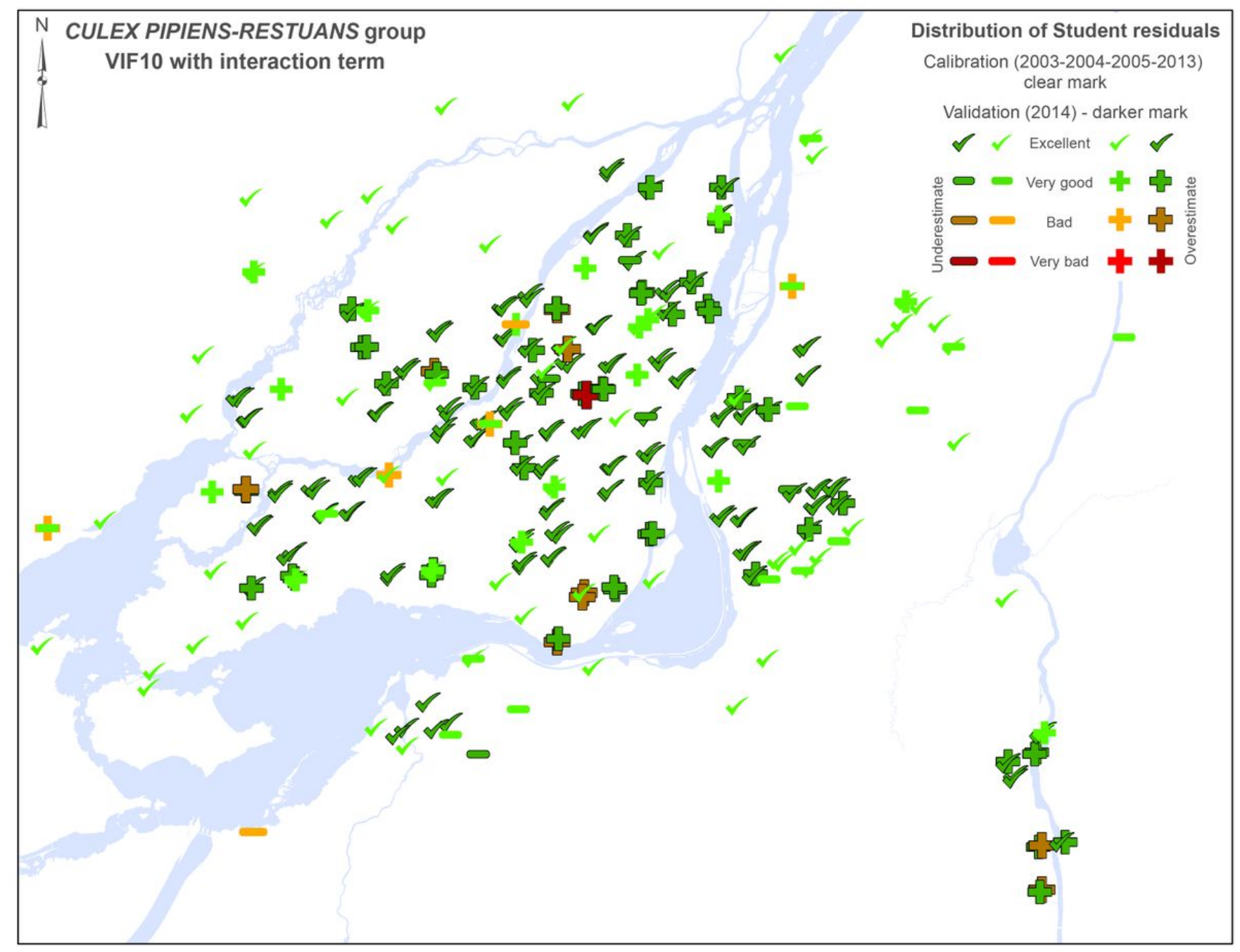

\section{Figure 3}

Distribution of Student residuals for the LMMwith10 model for the Culex pipiens-restuans group for the region of our study area where we found the majority of the entomological data including 2014 data (our validation dataset). 


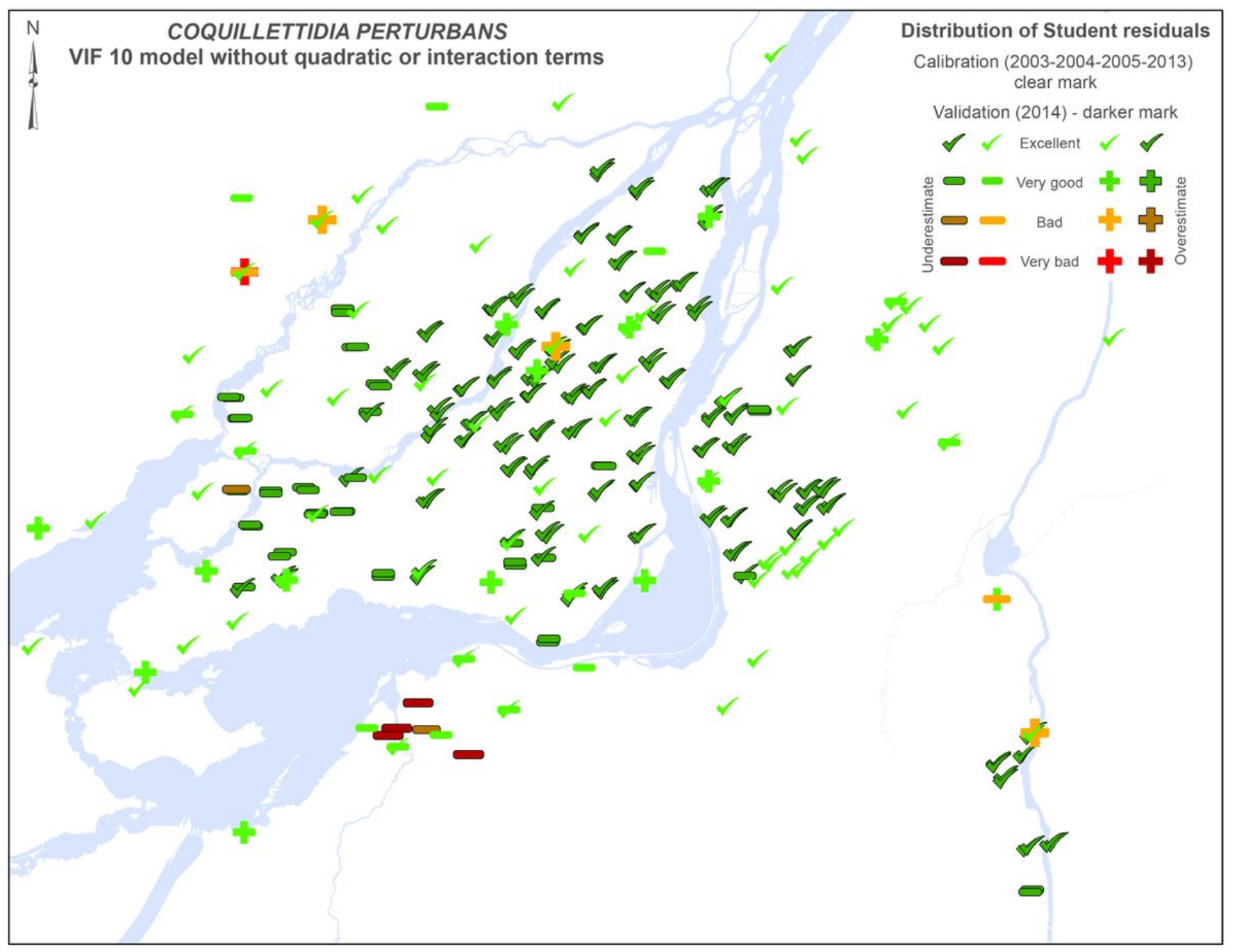

\section{Figure 4}

Distribution of Student residuals for the LMMwithout10 model for Coquillettidia perturbans for the region of our study area with the majority of the entomological data including 2014 data (our validation dataset). 


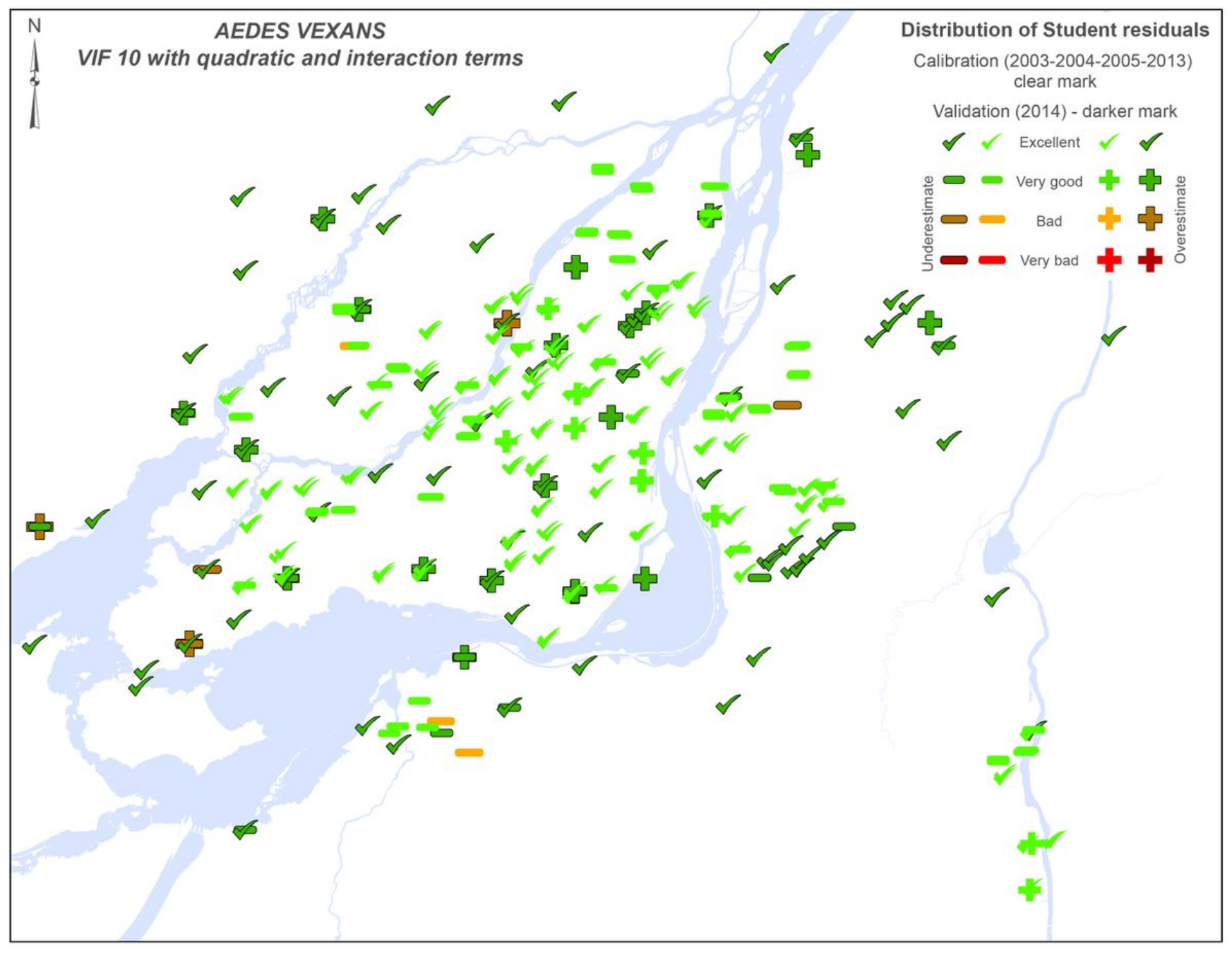

Figure 5

Distribution of Student residuals for the LMMwith10 model for Aedes vexans for the region of our study area with the majority of the entomological data including 2014 data (our validation dataset).

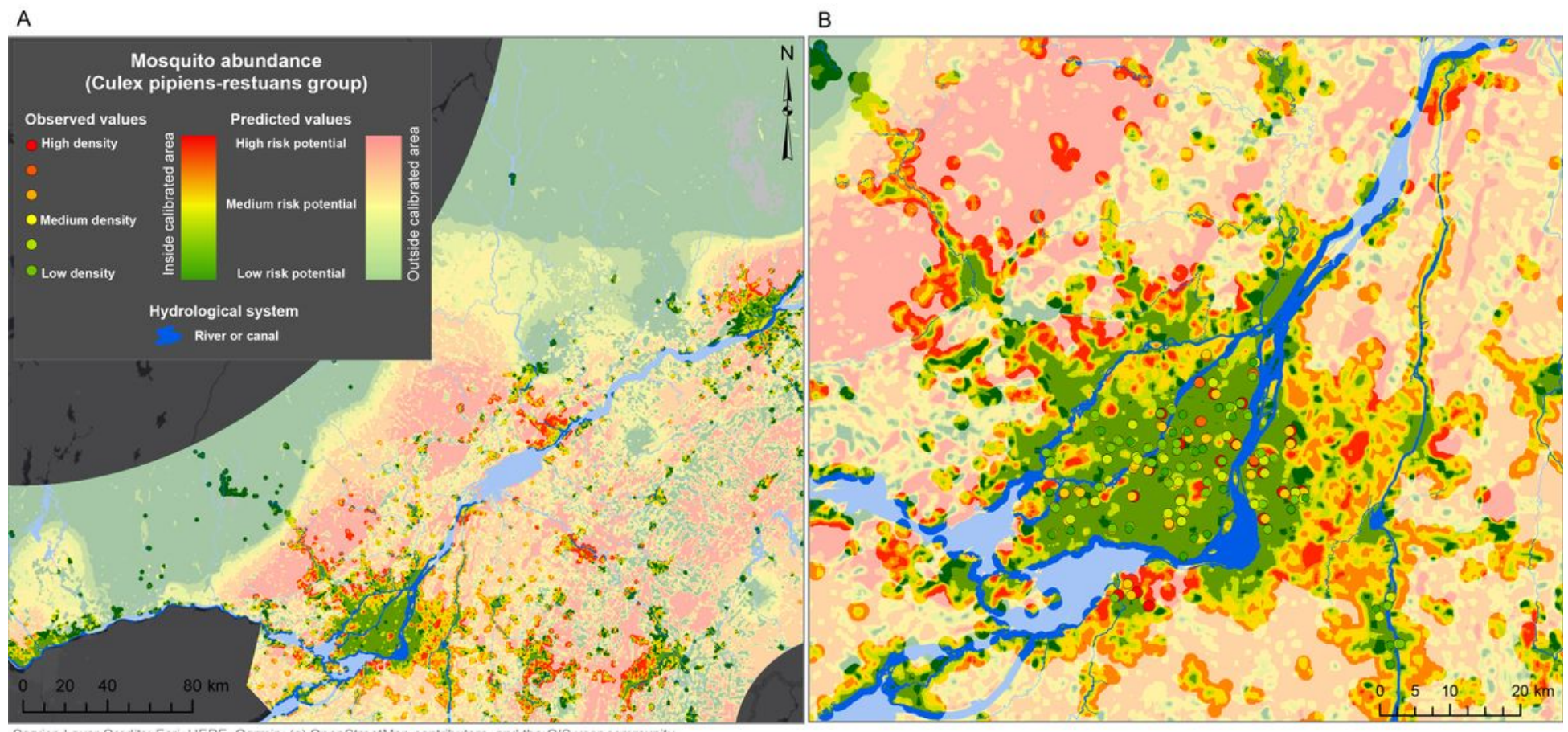


Mapping of spatial variations in mean annual abundances for Culex pipiens-restuans group (CPRg) for 2014 for (A) our entire study area, and (B) representation of values of observed data for a sub-area of our study area centred on the island of Montreal, with the highest density of entomological data.

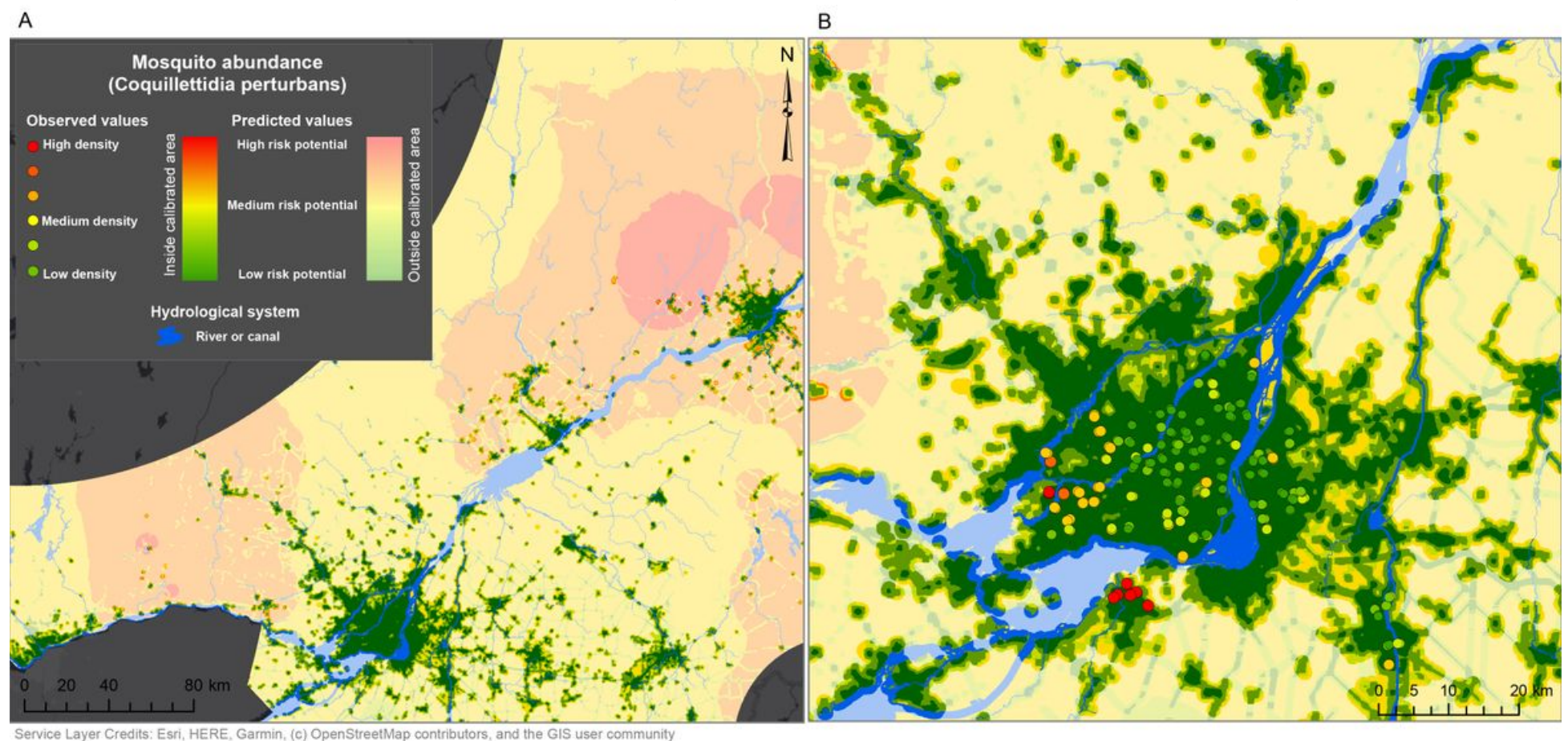

Figure 7

Mapping of spatial variations in mean annual abundances for Coquillettidia perturbans (CQP) for 2014 for(A) our entire study area, and (B) representation of values of observed data for a sub-area of our study area centred on the island of Montreal, with the highest density of entomological data.

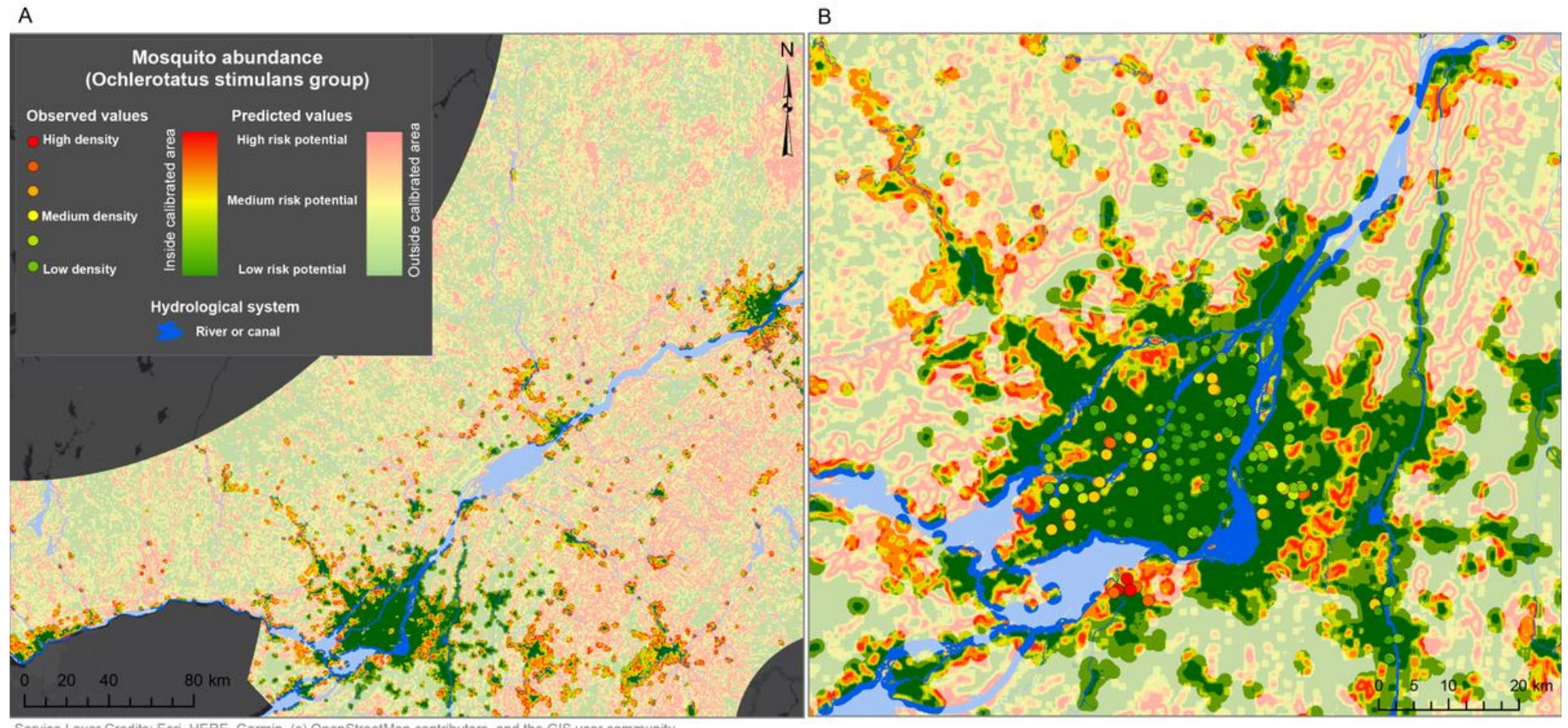

Figure 8

Mapping of spatial variations in mean annual abundances for Ochlerotatus stimulans group (STMg) for 2014 for (A) our entire study area, and (B) representation of values of observed data for a sub-area of our study area centred on the island of Montreal, with the highest density of entomological data. 
A

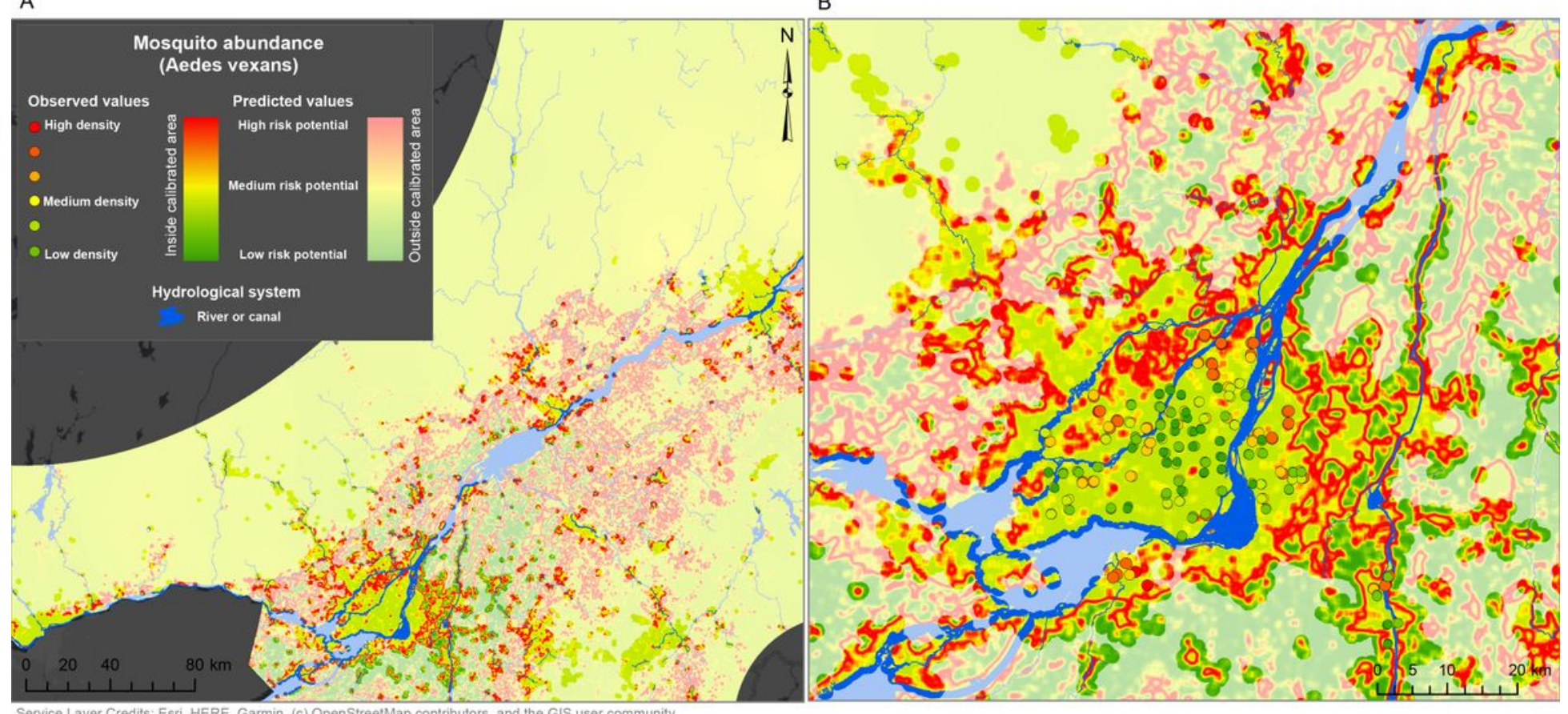

Figure 9

Mapping of spatial variations in mean annual abundances for Aedes vexans (VEX) for 2014 for (A) our entire study area, and (B) representation of values of observed data for a sub-area of our study area centred on the island of Montreal, with the highest density of entomological data. 